\title{
Association of age with glomerular filtration decrease
}

\section{Asociación de la edad con la disminución del filtrado glomerular}

\author{
Norma A. Balderas-Vargas, ${ }^{1}$ José Legorreta-Soberanis ${ }^{2}$ and Sergio Paredes-Solís ${ }^{2 *}$ \\ ${ }^{1}$ Family Medicine Unit 29, Instituto Mexicano del Seguro Social, Guerrero Delegation; ${ }^{2}$ Tropical Diseases Research Center, Universidad Autónoma \\ de Guerrero. Acapulco, Gro., Mexico
}

I would appreciate the publication of this letter related to the comment by Dr. Diego H. Ramírez-Leyva ${ }^{1}$ about our study. ${ }^{2}$ We agree with his remarks, in the sense that the older the age, the greater the decrease in renal function and, for this reason, as the result of the research indicated, being 60 years old or older was associated with occult renal failure. In the analysis, we found this more robust association after that age. We did not declare that it is a risk factor, we only showed its strength of association and evaluated the independence of this factor on the effect of the other significantly associated variables in the multivariate analysis.

The purpose of the study was not to find kidney function indicators according to patients' age. We estimated glomerular filtration rate with the most accepted proposal proposal, ${ }^{3}$ the Chronic Kidney Disease-Epidemiology Collaboration equation, which includes age in the calculation and allows the results to be compared with other national and international studies.

As for the association of systemic arterial hypertension control and type 2 diabetes mellitus, there was a non-significant association with both variables (see table 2 of the article). Measurement of the evolution time of these diseases was investigated (see the Material and methods section of the article); however, given that it entails an important information bias, it was not included in the analysis. For example, the 2012 National Health and Nutrition Survey identified 22.4 million adults with systemic arterial hypertension, and only half of them knew they suffered from it; ${ }^{4}$ for this reason, estimating the disease evolution time is highly inaccurate.

\section{Conflict of interests}

The authors declare that they have no conflicts of interest.

\section{Funding}

The authors did not receive any sponsoring to carry out this article.

\section{References}

1. Ramírez-Leyva HR. Disminución del filtrado glomerular con la edad, un fenómeno normal. Gac Med Mex. 2021;157:359.

2. Balderas-Vargas NA, Legorreta-Soberanis J, Paredes-Solís S, Flores-Moreno M, Serrano-de los Santos FR, Andersson N. Insuficiencia renal oculta y factores asociados en pacientes con enfermedades crónicas. Gac Med Mex. 2021;157:11-6.

3. Montañés-Bermúdez R, Bover-San Juan J, Oliver-Samper A, Ballarín-Castán JA, Gracia-García S. Valoración de la nueva ecuación CKD-EPI para la estimación del filtrado glomerular. Nefrología. 2010;30(2):185-94.

4. Instituto Nacional de Salud Pública. Encuesta Nacional de Salud y Nutrición 2012. Resultados Nacionales. México: Instituto Nacional de Salud Pública; 2012. 